Instability of Equilibria in Experimental Markets: Upward-Sloping Demands, Externalities, and Fad-Like Incentives

Author(s): Charles R. Plott and Jared Smith

Source: Southern Economic Journal, Vol. 65, No. 3 (Jan., 1999), pp. 405-426

Published by: Southern Economic Association

Stable URL: http://www.jstor.org/stable/1060807

Accessed: 24/02/2014 19:38

Your use of the JSTOR archive indicates your acceptance of the Terms \& Conditions of Use, available at http://www.jstor.org/page/info/about/policies/terms.jsp

JSTOR is a not-for-profit service that helps scholars, researchers, and students discover, use, and build upon a wide range of content in a trusted digital archive. We use information technology and tools to increase productivity and facilitate new forms of scholarship. For more information about JSTOR, please contact support@jstor.org. 


\title{
Instability of Equilibria in Experimental Markets: Upward-Sloping Demands, Externalities, and Fad-Like Incentives
}

\author{
Charles R. Plott* and Jared Smith $\dagger$
}

\begin{abstract}
The objective of the paper is to study markets in which the value of the activity to any one person increases with the level with which the activity is undertaken by others. The general interpretation could be fads, mimicking behavior, or some sort of belief formation process in which the beliefs or expectations of agents about some underlying state of nature are influenced by the buying behavior of other agents. The result is to create a market that can be modeled as having an upward-sloping market demand curve. The questions posed are (i) in the fad-like environment, does the classical concept of equilibrium (as an equating of market demand and market supply) accurately predict market behavior; (ii) can both stable and unstable equilibria be observed; and (iii) which of the two classical concepts of stability best describes the conditions under which instability is observed? Under the conditions of a fad-like demand side externality in a market organized by the multiple unit double auction (MUDA), market equilibration occurs at a point where demand equals supply. The disequilibrium behavior follows the dynamics of the Marshallian model of dynamics, as opposed to the Walrasian model. These results confirm and extend the major findings of Plott and George who studied a similar environment with a downward-sloping supply.
\end{abstract}

\section{Introduction}

This paper addresses four questions: (i) Can an upward-sloping demand be successfully created in a laboratory environment through the introduction of an externality, similar to fadlike preferences? (ii) In the presence of such special characteristics, do markets equilibrate to the classical intersection of the demand and supply curves? (iii) Can both stable and unstable equilibria be observed? This is a rather deep question since it asks if markets obey laws of dynamics similar to those that have been observed in physics. (iv) If markets do exhibit instability, which of the two classical concepts of stability, Marshallian stability or Walrasian stability, does the best job of predicting the conditions under which instability will be observed? Both of these theories are based on very general models of market behavior and so should apply to the simple and special case of an experimental setting. Indeed, the theories should apply to an experimental setting with the same force that would be applied to any other setting. Thus, experimental methods are a perfect way to address the issues, especially when no alternative method seems to exist.

* Charles R. Plott, Division of the Humanities and Social Science 228-77, California Institute of Technology, Pasadena, CA 91125, USA; E-mail cplott@hss.caltech.edu; Corresponding author.

$\dagger$ A former student at the California Institute of Technology, Pasadena, CA, USA.

The financial support of the National Science Foundation and the Caltech Laboratory for Economics and Political Science is gratefully acknowledged. The research assistant work of Daniel J. Richardson is appreciated.

Received May 1997; accepted August 1998. 
The questions posed are natural. First, a fundamental part of neoclassical theory of market adjustments resides in the presumption that markets can be unstable. Thus, there is a natural intellectual curiosity about whether or not the presumption is correct. Second, there is a practical motivation for an interest in stability. Multiple equilibria often appear in models, causing difficulty with model specification. The conventional solution to the problem is to discard the equilibria that are unstable under the presumption that unstable equilibria cannot be observed, that is, they are removed from all consideration. It is only natural to ask if this convention is justified. The third question stems from an issue about the relationship between the competitive model of markets and game theory. The most basic principles of economics are being replaced by principles of game theory and related solution concepts. Do phenomena exist in markets that will be very difficult if not impossible to capture with the static solution concepts of game theory? In particular, game theory and the associated concepts of solutions tend to be equilibrium theories, without any accompanying notion of dynamics or equilibration. Thus, since disequilibrium is a primary feature of instability, it is a rather obvious place to look for challenges to the static equilibrium concepts of game theory.

Notice that the motivations for this study are essentially unrelated to parameters that might be found in the U.S. economy, or any other economy, for that matter. The motivations are not about the economy; they are about economics and the underlying principles of economics that we use as tools to understand the economy. At this stage, the investigation is strictly of a laboratory nature. While the study suggests many interesting questions about the nature of markets found in the field, they are not addressed here. For example, the question of the relative frequency or instances of instability are not addressed. Measures that might indicate when a market is perched at an unstable equilibrium are not sought. This study is about the nature of the laws that govern whether or not an equilibrium is stable, and the focus is on the behavior of markets in the laboratory.

Once one decides to look for instability, the neoclassical theory itself suggests where to search. According to the ideas, the curves must have a perverse shape in the sense that the demand curve should slope upward or the supply curve should slope downward. Neoclassical theory also suggests two types of underlying economic circumstances that can produce such perversities. One set of circumstances is related to income effects. Both the famous Giffen good of upward-sloping demands and the labor-leisure tradeoff that produces backward-bending (downward-sloping) supply curves are related to the income effect. A second set of circumstances is related to externalities or external economies, as Marshall called them. On the supply side, downward-sloping supplies are thought to be produced by efficiencies that might be produced by expanding industrial scale. On the demand side, a similarly constituted externality can produce the upward-sloping demand curves that are thought to be produced by preferences such as desires to mimic the behavior of others.

This paper employs the second set of circumstances, the use of externalities to create an upward-sloping demand. ${ }^{1}$ Markets were created in which the value of the units to any one person increased with the level with which the units are purchased by others. The more others do it, the more any particular individual wanted to do it. The general interpretation could be preferences that result in a desire to mimic others or it could be some sort of belief formation process in which the beliefs or expectations of agents about some underlying state of nature

\footnotetext{
'Experimental studies of externalities in markets have reported that the competitive model works exactly as expected.
} (See Plott 1983; Harrison et al. 1987.) 
are influenced by the buying behavior of other agents. The result of the preference inducement was to create a market that can be modeled as having an upward-sloping market demand curve even though individual demand curves are downward sloping. With such a demand, an opportunity arose to observe whether or not instability presents itself.

Based on previous research, a presumption exists that Marshallian stability and not Walrasian stability will be observed. Plott and George (1992) studied markets in which the supply was downward sloping due to a Marshallian externality and found that the Marshallian model of market stability provided the appropriate conditions under which instability could be observed. The Walrasian concept of stability was found to be completely inappropriate for that type of economic environment. Since an upward-sloping demand is a mirror image of the Marshallian downward-sloping supply, the current study is a test of both the replicability and the robustness of the Plott and George experimental results.

The results are easy to summarize. Unstable equilibria can exist in markets. They exist at the intersection of demand and supply, as do other classical market equilibria. Where the perverse curves are due to an externality, the Marshallian model and not the Walrasian model define the conditions under which unstable equilibria exist. The experiments replicate and extend the results previously reported by Plott and George.

Aside from classical discussions, the literature about the possibility of upward-sloping demands is not extensive. Papers by Becker (1991) and Karni and Levin (1994) both addressed issues of fad-like preferences. (For brevity, we will refer to them as B\&KL.) Interestingly enough, both sets of authors, $B \& K L$, failed to realize that they were dealing with a classical Marshallian external economy on the demand side as opposed to the supply side. After translation to the demand side, the model of B\&KL differs from Marshall and Plott and George (1992) (PG) in only two substantive respects. The first is the structure of the externality and the second is the assumed industrial organization.

First, with respect to the structure of the externality, B\&KL do not require that the level of market activity be the vehicle that carries the externality, as do Marshall and PG. Instead, B\&KL fads allow market demand to be the vehicle of the externality independent of whether or not the demand resulted in trades or whether adequate supply exists. By contrast, the formal representation of the externality used in PG depends on actual volume traded in the market (Marshallian fads). In B\&KL fads, the utilities of agents depended on the number of people that want to do something rather than the incidence of them actually doing it, as is the case in Marshall fads and in PG.

Second, with respect to the industrial organization, B\&KL assume that there are only a small number of well-informed sellers and many myopic buyers. By contrast, Marshall and PG assume that there is symmetry between the buying and selling sides of the market. The implications of these differences are rather dramatic. Marshall and PG apply the competitive model on the one hand and with it can characterize notions of stable and unstable markets together with possible dynamic adjustment processes. By contrast, B\&KL allow the demand side to behave much like competitors, from which a demand function can be derived in the same way that it is derived in this paper. However, that is where the similarity ends. In this paper, the supply is also derived by application of the competitive model. In B\&KL, the sellers are fully informed of the behavior of the demand side of the market and are able to solve for various equilibria using standard game theoretic logic. The problem posed by B\&KL is then one of selecting the appropriate equilibrium by appeal to solution concepts.

While both sets of authors, B\&KL, mention stability, they do not use the term in a classical 
sense. In fact, it is interesting to note that, to the extent that the term stability makes sense, they identify instability with Walras and not Marshall. Thus, as the data reported in this paper show, the intuitive ideas of instability that they apply are exactly the opposite of what they should use.

The organization of the paper is as follows. Section 2 is a review of the two competing models of market adjustment, Marshallian and Walrasian. This section is also used to introduce the major features of the experimental design. Sections 3 and 4 are brief summaries of the formal structure of the externality model and the associated concepts of demand and equilibrium from the point of view of the individual and the market, respectively. Section 5 is a discussion of the market supply functions. Section 6 is an outline of the experimental design and the predictions of the models, given the parameters imposed. Section 7 discusses experimental procedures. Section 8 contains the experimental results. The final section is a summary of the conclusions. An appendix contains forms and instructions.

\section{Marshall, Walras, and the Experimental Strategy}

Suppose the market is characterized by an upward-sloping demand such as drawn in Figure $1, D_{1} D_{1}$. This is only a crude approximation of the actual parameters that were induced in the experiment. Exactly how they were induced will be described in later sections. For now, the curve will be used to describe the difference between the Walrasian and the Marshallian models of market adjustment. ${ }^{2}$ Consider also the upward-sloping supply curve $S_{1} S_{1}$. There are four potential equilibria, points $a, b, c$, and $d$. In addition, the actual intersection of the curves is not the behavioral intersection because of a transaction cost that is always observed in markets. Units for which there are exactly no gains from trade will not trade. Thus, a small gap exists between demand and supply at equilibrium.

Let $D(p)$ and $S(p)$ be the quantities demanded and supplied at a particular price and let $P_{D}(q)$ and $P_{S}(q)$ be the demand price and supply price, respectively, at some quantity $q$. The two models of adjustment are

$$
\begin{array}{lll}
\text { Walras: } & \partial p / \partial t=F(D(p)-S(p)) \\
\text { Marshall: } & \partial q / \partial t=G\left(P_{D}(q)-P_{S}(q)\right) .
\end{array}
$$

So the Walrasian model postulates that price adjusts with a speed dictated by the difference between quantity demanded and quantity supplied at the price. The theory is silent about quantity. The Marshallian model postulates that quantity adjusts with a speed dictated by the difference between the demand price and the supply price evaluated at the quantity. The theory is silent about price. Both theories were developed on special "as if" assumptions about the nature of the adjustment process. For example, Marshall assumed a special trading in which the high valued and low cost units trade in sequence. Walras assumed the market was a tâtonnemont system. These assumptions allow the theories of dynamics to proceed by observing only one of the variables (price or quantity) while neglecting the other. Of course, the derivative of both $F$ and $G$ is positive.

\footnotetext{
${ }^{2}$ Summaries of related ideas derived from classical and neoclassical discussions can be found in Henderson and Quandt (1980) and in Takayma (1974).
} 


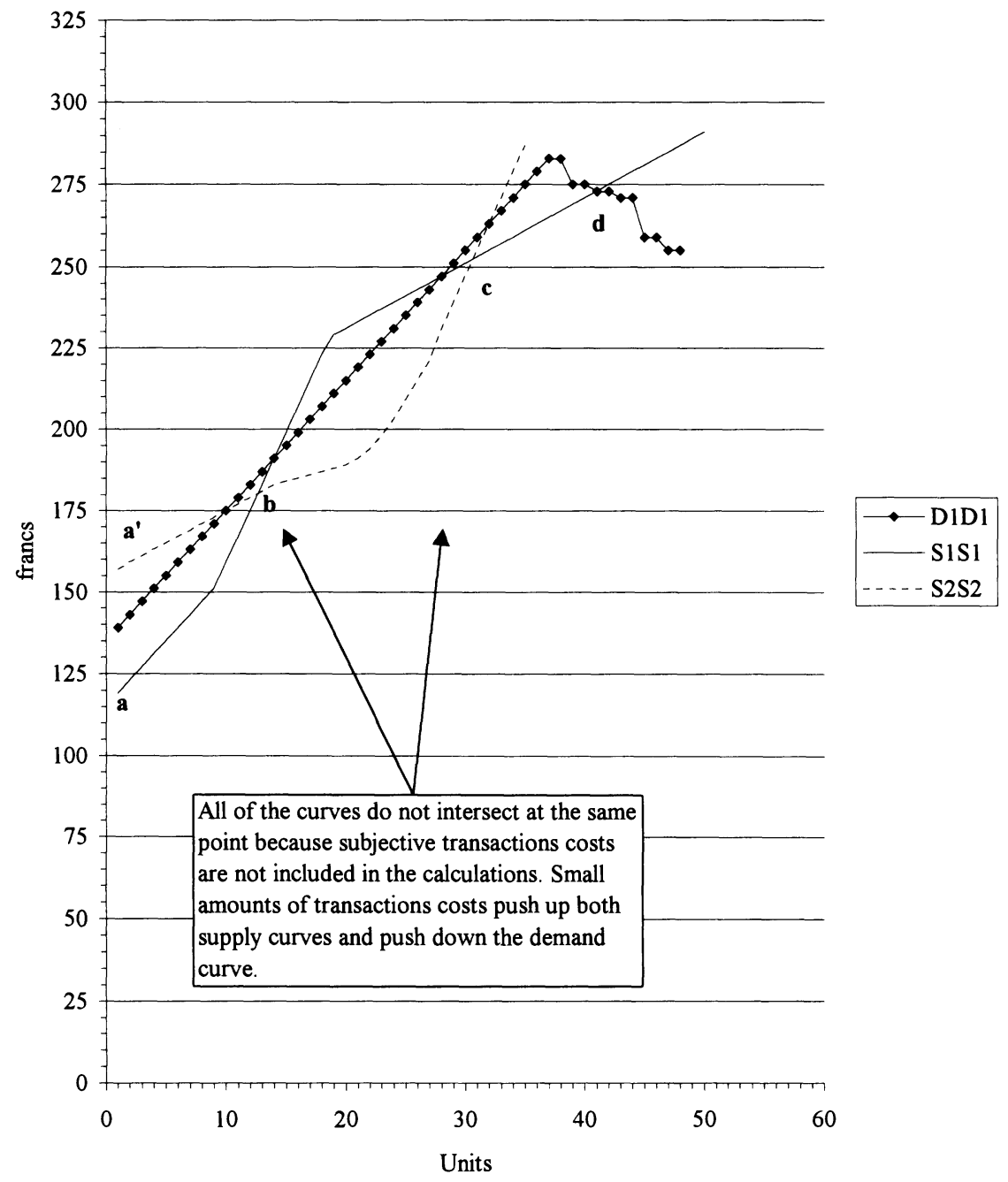

Figure 1. Market Demand $D_{1} D_{1}$ and Two Supply Functions $S_{1} S_{1}$ and $S_{2} S_{2}$

The substantial difference between the theories can be seen in Figure 1. Under supply conditions $S_{1} S_{1}$, point $b$ is stable according to the Marshallian model but is unstable under the Walrasian model, that is, if the price moves slightly upward, away from $b$, then according to the Walrasian model, demand is greater than supply so price continues to go up. On the other hand, if quantity increases slightly beyond point $b$, then according to the Marshallian model, the supply price is greater than demand price and the quantity will fall back to $b$. Point $a$ is unstable under the Marshallian model, but it is stable according to Walras. Point $c$ is Walras stable and Marshallian unstable. Point $d$ is stable according to both models. Thus, the models give essentially opposite behavioral predictions.

Now, consider the supply curve $S_{2} S_{2}$. Points $a^{\prime}, b$, and $c$ are equilibria. However, now the stability properties are reversed. Point $b$ is stable according to the Walrasian model $\left(a^{\prime}\right.$ and $c$ are unstable) while point $b$ is unstable according to Marshall ( $a^{\prime}$ and $c$ are stable). Again, the models give essentially opposite behavioral predictions.

The single demand curve $D_{1} D_{1}$, shown in Figure 1, and the two supply curves demonstrate 
the logic of the experimental design. By beginning with $S_{1} S_{1}$ parameters, it is possible to discover whether or not the system moves toward one of the several equilibria. If it does, then we will know that the equilibrium of the demand and supply model captures market tendencies and the first two questions will be answered. Then, after the market equilibrates, a supply shift to $S_{2} S_{2}$ will make the equilibrium unstable according to the dynamics of the model that got it there, if indeed such laws of dynamics are operative. An equilibrium that was previously stable, presumably, has now become unstable. If the market then moves away from the equilibrium to which it had previously converged, then we have answers to questions iii and iv.

A possibility exists that market activity will stay at an unstable equilibrium because it is never perturbed away far enough to cause the underlying instability to become operative. After the shift in supply function, the market activity could simply stay at the equilibrium even though it has become unstable. To deal with this possibility the experimental design called for a push to the market. The dynamic model theoretically requires only a small push, but since we have no theory of what might be small, the plan called for something rather dramatic. If, after the shift, the market did not move, the demand would be shifted to $D_{2} D_{2}$ in Figure 2 . The method of accomplishing this will be discussed in later sections. Briefly summarized, the trick was to allow each subject to operate "as if" the volume of others was at least 15 units; that is, even if the volume of others was less than 15 , the subject's payoff was made as if the volume of others was 15 . If volume of others was more than 15 , then the subject's payment was based on the actual volume. As will be made clear below, the incentives were conditioned on the volume of others (an externality), and the resulting guarantee produced a normal downward-sloping demand up to 15 units of others because there was no externality. Beyond 15 , the externality existed so the upward-sloping character was again present. Figure 2 displays $D_{2} D_{2}$ in the presence of the supply curve $S_{2} S_{2}$ because this was the supply condition during the only time that the change in parameters was deployed. Under conditions $S_{2} S_{2}$ and $D_{2} D_{2}$, the only equilibrium is $c$, which is stable according to Marshallian principles of dynamics but is unstable according to Walrasian principles of dynamics.

\section{Underlying Theory of Demand and Individual Incentives}

The upward-sloping demand curve is the result of an externality. Each individual buyer makes decisions about one's own consumption based on prices and based on expectations about the decisions of others. In terms of the general theory, this relationship is captured by a utility function of the form $U\left(x_{i}, x_{-i}\right)$, where $x_{i}$ is own consumption and $x_{-i}$ is the consumption of others. Since the consumption of others may not be known at the time of decision, a distinction is made between $x_{-i}$ and $x_{-i}^{e}$, where $x_{-i}^{e}$ represents the beliefs of $i$ about the consumption activities of others. Of course, the beliefs could be represented by a probability distribution, but for purposes of these theories, the decision under uncertainty takes a very specialized form.

In a competitive model, each individual attempts to maximize $\mathrm{U}\left(x_{i}, x_{-i}\right)$ by choosing $x_{i}$ subject to the budget constraint and the beliefs about the activities of others. Given the special forms of beliefs, the problem becomes an attempt to maximize $\mathrm{U}\left(x_{i}, x_{-i}^{e}\right)$ subject to the budget constraint. As will be made clear in subsequent discussions, the equilibrium of the system will be defined by a rational expectations axiom that requires that all expectations about the behavior of others are accurate; that is, in equilibrium, the rational expectations requirement will be that 


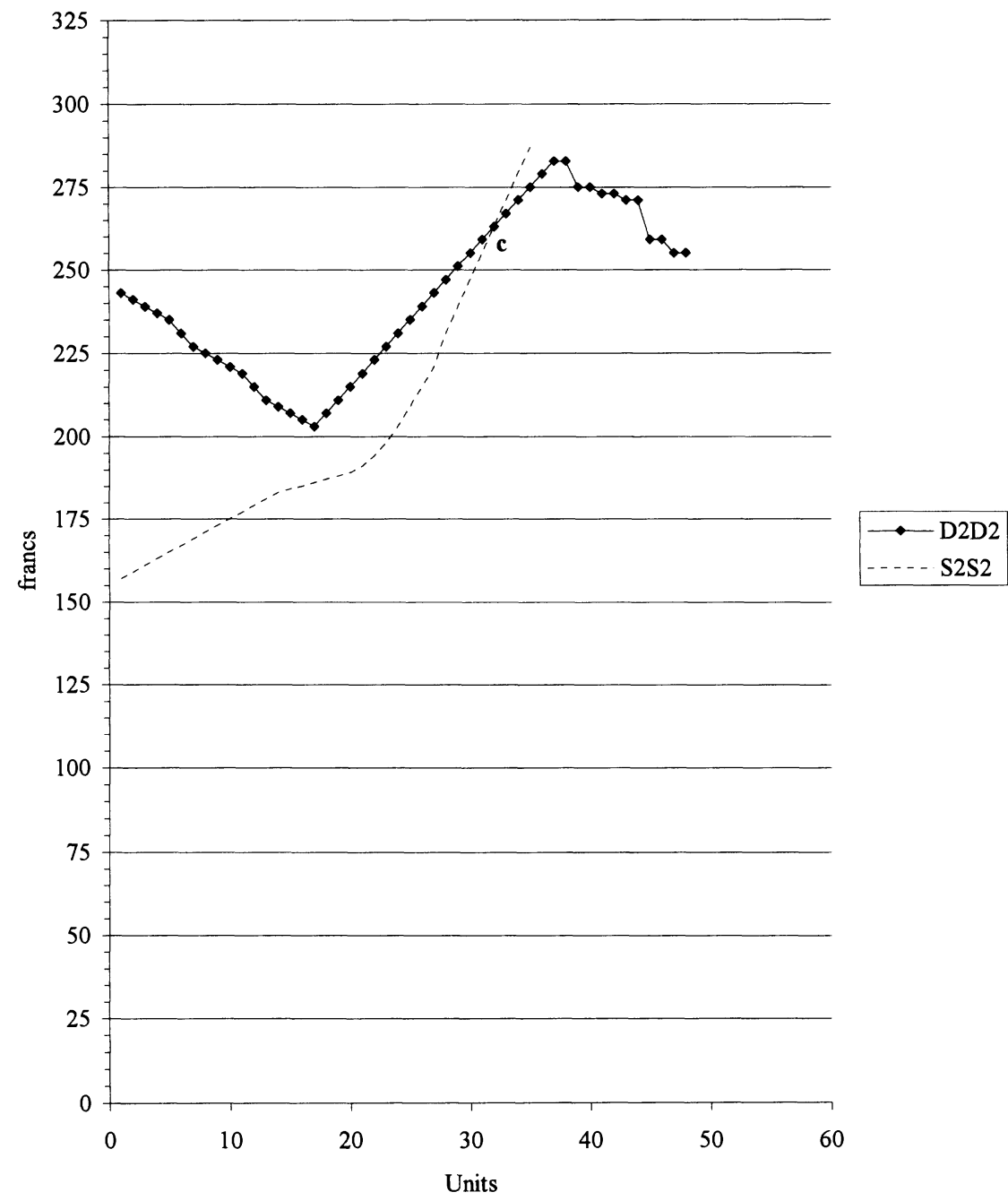

Figure 2. Market Demand Function $D_{1} D_{1}$ and Market Supply Function

$$
x_{-i}^{e}=x_{-i}=\sum_{j \neq i} x_{j}
$$

From an experimental design perspective, the most complicated aspect of individual incentives is the determination of redemption values for buyers because of the externality and resulting fad-like incentives. As any one agent buys more, the marginal value of units to other agents increases. The models of the experimental situation assume that agents prefer more money to less and that money is the only thing that the agents care about; that is, where $m_{i}$ is the amount of money earned by the subject in a given period of the experiment, the incentives on which the model is based are captured by the function $U^{i}\left(m_{i}\right)$. If the individual faces a competitive market price $P$, then the money income of agent $i$ is of the form

$$
m_{i}=R^{i}\left(x_{i}, x_{-i}\right)-P x_{l},
$$

where the function $R^{i}\left(x_{i}, x_{-i}\right)$ is the redemption value that the buyer receives from the experimenter. 
The specific functional form used in the experiments is

$$
R^{i}\left(x_{i}, x_{-i}\right)=a_{i} x_{i}-b_{i} x_{i}^{2} / 2+c_{i} x_{i} x_{-i},
$$

where $a, b$, and $c$ are constants that are determined by the experimenter. However, from an experimental point of view, the key functions are the marginals of redemption values in terms of the individual controls; that is,

$$
\partial R^{i}\left(x_{i}, x_{-i}\right) / \partial x_{i}=a_{i}-b_{i} x_{i}+c_{i} x_{-i} .
$$

Equation 3 is the basis of the incentive charts for buyers contained in the appendix. The experiment employed three different agent buyer types, and there were two subjects for each type. All buyers had identical parameters $b$ and $c$, with $b=16$ and $c=8$. The $a_{i}$ parameter differed according to type, with the value of $a \in\{132,136,140\}$. In the table, the units of $m$ are in francs and each franc is converted at a rate of 0.24 dollars per franc for buyers and 0.01 dollars per franc for sellers.

An approximation of this function is shown in Figure 3 for individual 0. Shown here are the marginal redemption values for various units given that the volume of others is $5,10,15$, and 20 , respectively. As can be seen, the redemption values for the individual decrease as units purchased increase, given that the purchases of others are constant. However, if purchases of others go up, then the marginal values for this individual go up. Shown also in the figure is the market demand for this individual. It will be explained in the next section.

\section{Underlying Theory of Demand and Market Parameters}

Since all buyers and sellers were in essence given interest-free loans for the duration of a period, they have no budget constraint. In this case, the maximization hypothesis dictates that the buyers will behave as if they were attempting to satisfy the equation $\partial U\left(m_{i}\left(x_{i}, x_{-i}^{e}\right)\right) / \partial x_{i}=$ 0 . Since utility is assumed to be monotone in money earnings, the hypothesis is that the individual attempts to maximize money income given the beliefs about the transactions of others; that is, the variable $x_{-i}$ is replaced by a different variable $x_{-i}^{e}$ in the model of the individual's decisions. From Equations 1, 2, and the hypothesis about beliefs, this becomes

$$
\partial U\left(m_{i}\left(x_{i}, x_{-i}^{e}\right)\right) / \partial x_{i}=a_{i}-b_{i} x_{i}+c_{i} x_{-i}^{e}-P=0
$$

or, using Equation 3, it becomes an implicit market demand equation for the individual,

$$
\partial R^{i}\left(x_{i}, x_{-i}^{e}\right) / \partial x_{i}=a_{i}-b_{i} x_{i}+c_{i} x_{-i}^{e}=P .
$$

By solving for $x_{i}$ in terms of $P$ and $x_{-i}^{e}$, Equation 5 becomes the amounts the individual would want to purchase expressed as a function of prices and their beliefs about the purchases of others.

Figure 3 contains a graph of the demand function implicit in Equation 5 for individual 0 , given beliefs about the transactions of others. If the other individuals purchase five units and if the price is 155 francs, then this individual would want to purchase one unit. If the price was 179 francs and if others purchased 10 units, then this individual would want to purchase 2 units. If the price was 203 francs and if others purchased 15 units, then this individual would want to purchase 3 units. Thus, one can obtain an intuition of how a market demand might have an upward slope if increasing prices were associated with more purchases by others. 


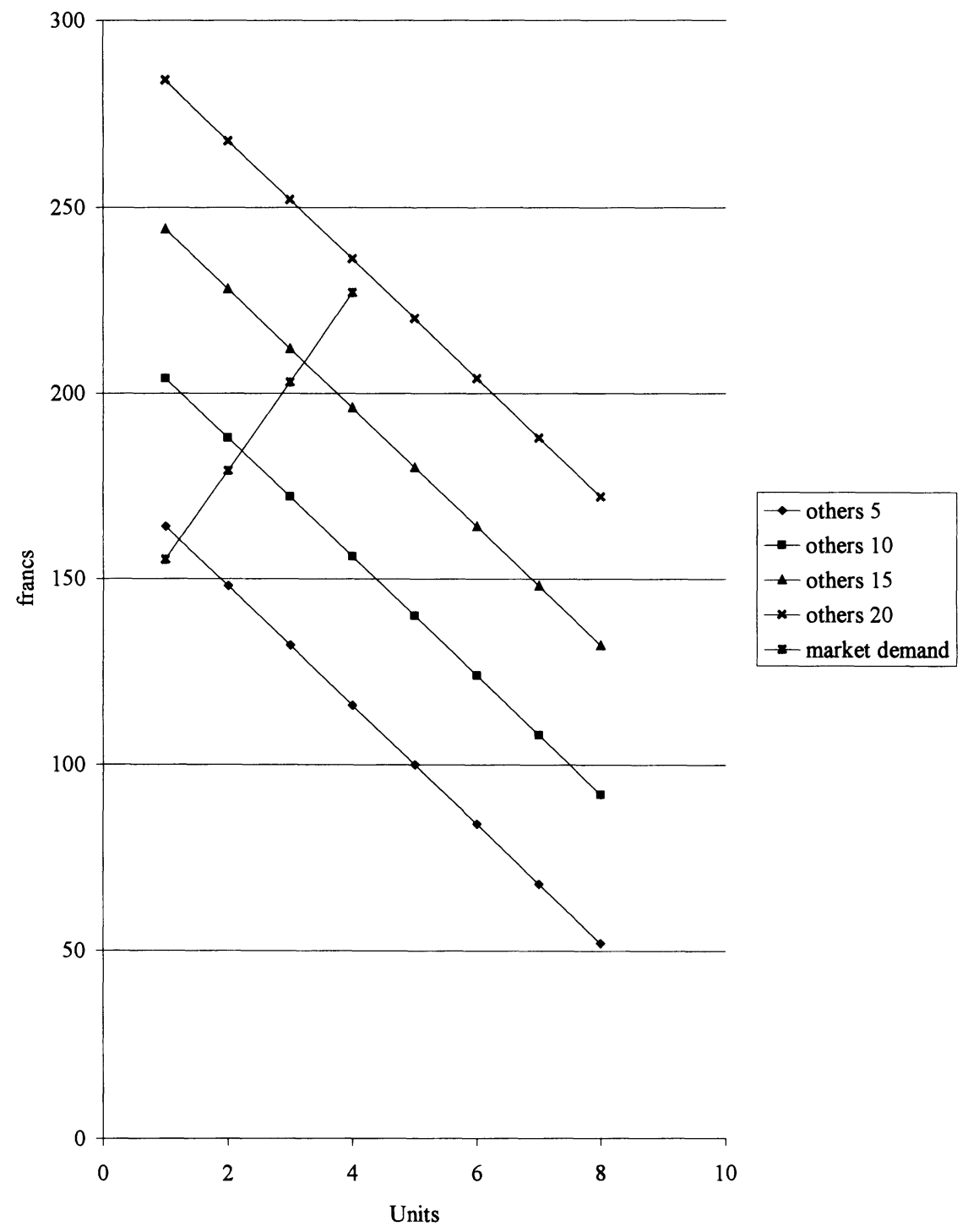

Figure 3. Individual Incentive Shown as a Function of Own Units Purchased and Units Purchased by Others for Subject 0

The simultaneous relationship between prices and purchases of others is used by the competitive model to produce the upward-sloping demand. The theory requires that, for a price and quantity to be an equilibrium on the demand side of the market, each individual is optimizing given the price; that is, Equation 5 must be satisfied for each individual. Second, the theory requires that the expected sales of others equals the actual sales. No buyer is surprised by what other buyers do. This is a type of rational expectations axiom. In particular

$$
x_{-i}^{e}=x_{-i}=\sum_{j \neq i} x_{j}
$$

Equation 5 is the vehicle that ties expected transactions to the actual transactions of the individual. Equation 6 ties the beliefs of the individual about the behavior of others to the actual behavior of others. Specifically, it requires that the beliefs are accurate. 
Substituting the parameters for the experiment and solving the resulting expressions of Equations 5 and 6 yields a continuous approximation of market demand. The calculations for both $D_{1} D_{1}$ and $D_{2} D_{2}$ are shown in Table 1 . For example, for $D_{1} D_{1}$, the parameters are $\{132$, $136,140\}$ for the values of $a_{i}$ for each of the types. There are two agents of each type yielding a total of six agents on the demand side. The values of $b$ and $c$ are the same for all agents and are, respectively, 16 and 8 . Substituting and solving the resulting market demand function thus derived is approximately

$$
P=4 X+136
$$

Notice that the demand function has a positive slope. The computations in the table differ slightly due to the discrete nature of the units that compose the table.

\section{Market Supply}

Parameters supporting two different supply functions are utilized in the experiments. These are seen as $S_{1} S_{1}$ and $S_{2} S_{2}$ in Figure 1. The numerical parameters are contained in Table 1. These curves were induced using standard procedures. An example of a seller's cost sheet is contained in the appendix. As will be explained in the next section, these two different supply functions imply different stability properties when market demand is $D_{1} D_{1}$.

\section{Experimental Design and Model Predictions}

The experimental design called for the market to first contain the demand parameters $D_{1} D_{1}$ and the supply parameters $S_{1} S_{1}$. These parameters were to stay in place for period 0 through period 8. Pilots and previous experiments suggested that this was sufficient time to give the system an opportunity to equilibrate at one of the several equilibria. In period 9, the supply curve was shifted to $S_{2} S_{2}$. The demand curve would remain unchanged at $D_{1} D_{1}$ and the supply shift would be implemented in a manner that was undetected by the demand side of the market. The effect of this shift in supply would be to reverse the stability properties of all of the equilibria according to both theories. Thus, all stable equilibria according to a given theory would become unstable according to that theory and all unstable equlibria would become stable (with some exceptions at the extreme and boundaries). Thus, if markets have elements of the dynamics captured by either of the two theories, then prices and quantities would move away from the equilibrium to which they had previously converged, and this to and fro behavior would isolate the nature of the dynamics involved. If no movement took place, if the prices and quantities remained at a possible unstable equilibrium, then the design called for the implementation of demand curve $D_{2} D_{2}$. This shift in demand would provide a push that could further test the dynamics.

The equilibria under the various conditions are listed in Table 2 . As can be seen, with the exception of the outermost equilibrium under conditions $S_{1} S_{1}$, all equilibria have opposing stability properties depending on the theory applied. And, after the supply shift, the stability properties are reversed. 
Table 1. Induced Market Demands and Market Supplies

\begin{tabular}{|c|c|c|c|c|}
\hline Quantity & $D_{1} D_{1}(q)$ & $S_{1} S_{1}(q)$ & $S_{2} S_{2}(q)$ & $\begin{array}{l}D_{2} D_{2}(q) \text { with } \\
\text { Guarantee }\end{array}$ \\
\hline 1 & 139 & 119 & 157 & 243 \\
\hline 2 & 139 & 123 & 159 & 243 \\
\hline 3 & 143 & 127 & 161 & 239 \\
\hline 4 & 147 & 131 & 163 & 239 \\
\hline 5 & 151 & 135 & 165 & 235 \\
\hline 6 & 155 & 139 & 167 & 235 \\
\hline 7 & 159 & 143 & 169 & 227 \\
\hline 8 & 163 & 147 & 171 & 227 \\
\hline 9 & 167 & 151 & 173 & 223 \\
\hline 10 & 171 & 159 & 175 & 223 \\
\hline 11 & 175 & 167 & 177 & 219 \\
\hline 12 & 179 & 175 & 179 & 219 \\
\hline 13 & 183 & 183 & 181 & 211 \\
\hline 14 & 187 & 191 & 183 & 201 \\
\hline 15 & 191 & 199 & 184 & 207 \\
\hline 16 & 195 & 207 & 185 & 207 \\
\hline 17 & 199 & 215 & 186 & 203 \\
\hline 18 & 203 & 223 & 187 & 203 \\
\hline 19 & 207 & 229 & 188 & 211 \\
\hline 20 & 211 & 231 & 189 & 211 \\
\hline 21 & 215 & 233 & 191 & 219 \\
\hline 22 & 219 & 235 & 194 & 229 \\
\hline 23 & 223 & 237 & 198 & 227 \\
\hline 24 & 227 & 239 & 203 & 227 \\
\hline 25 & 231 & 241 & 209 & 235 \\
\hline 26 & 235 & 243 & 215 & 235 \\
\hline 27 & 239 & 245 & 221 & 243 \\
\hline 28 & 243 & 247 & 231 & 243 \\
\hline 29 & 247 & 249 & 239 & 251 \\
\hline 30 & 251 & 251 & 247 & 251 \\
\hline 31 & 255 & 253 & 255 & 259 \\
\hline 32 & 259 & 255 & 263 & 259 \\
\hline 33 & 263 & 257 & 271 & 267 \\
\hline 34 & 267 & 259 & 279 & 267 \\
\hline 35 & 271 & 261 & 287 & 275 \\
\hline 36 & 275 & 263 & 295 & 275 \\
\hline 37 & 279 & 265 & 303 & 283 \\
\hline 38 & 283 & 267 & 311 & 283 \\
\hline 39 & 283 & 269 & 319 & 275 \\
\hline 40 & 275 & 271 & 327 & 275 \\
\hline 41 & 275 & 273 & 335 & 273 \\
\hline 42 & 273 & 275 & 343 & 273 \\
\hline 43 & 273 & 277 & 351 & 271 \\
\hline 44 & 271 & 279 & 359 & 271 \\
\hline 45 & 271 & 281 & 367 & 259 \\
\hline 46 & 259 & 283 & 375 & 259 \\
\hline 47 & 259 & 285 & 383 & 255 \\
\hline 48 & 255 & 287 & 391 & 255 \\
\hline 49 & 255 & 289 & 399 & \\
\hline 50 & & 291 & 407 & \\
\hline
\end{tabular}


Table 2. Equilibria $(P, q)$ and Stability Properties: Walrasian, Marshallian, Stable and Unstable

\begin{tabular}{|c|c|c|c|c|c|c|c|c|}
\hline \multicolumn{3}{|c|}{$\begin{array}{c}\text { Supply Conditions } \\
S_{1} S_{1}\end{array}$} & \multicolumn{3}{|c|}{$\begin{array}{l}\text { Supply Conditions } \\
\qquad S_{2} S_{2}\end{array}$} & \multicolumn{3}{|c|}{$\begin{array}{l}\text { Supply Conditions } \\
S_{2} S_{2} \text { with Demand } \\
\text { Guaranteed Volume }\end{array}$} \\
\hline $\begin{array}{l}\text { Point } \\
\text { on } \\
\text { Figure } \\
1\end{array}$ & $P, q$ & $\begin{array}{l}\text { Stability } \\
\text { Properties }\end{array}$ & $\begin{array}{c}\text { Point } \\
\text { on } \\
\text { Figure } \\
1\end{array}$ & $P, q$ & $\begin{array}{l}\text { Stability } \\
\text { Properties }\end{array}$ & $\begin{array}{c}\text { Point } \\
\text { on } \\
\text { Figure } \\
1\end{array}$ & $P, q$ & $\begin{array}{l}\text { Stability } \\
\text { Properties }\end{array}$ \\
\hline$a$ & 119,0 & Walras stable & $a^{\prime}$ & 154,0 & $\begin{array}{l}\text { Marshallian sta- } \\
\text { ble }\end{array}$ & & & \\
\hline$b$ & 176,12 & $\begin{array}{l}\text { Walras unstable, } \\
\text { Marshallian } \\
\text { stable }\end{array}$ & $b$ & 176,12 & $\begin{array}{l}\text { Walras stable, } \\
\text { Marshallian } \\
\text { unstable }\end{array}$ & & & \\
\hline$c$ & 248,30 & $\begin{array}{l}\text { Walras stable, } \\
\text { Marshallian } \\
\text { unstable }\end{array}$ & $c$ & 248,30 & $\begin{array}{l}\text { Walras unstable, } \\
\text { Marshallian } \\
\text { stable }\end{array}$ & $c$ & 248,30 & $\begin{array}{l}\text { Walras unstable, } \\
\text { Marshallian } \\
\text { stable }\end{array}$ \\
\hline$d$ & 273,40 & $\begin{array}{l}\text { Walras stable, } \\
\text { Marshallian } \\
\text { stable }\end{array}$ & & & & & & \\
\hline
\end{tabular}

\section{Experimental Procedures}

A total of three experiments was conducted plus pilot experiments. These are indexed by the dates on which the experiments were conducted (021592, 022292, and 030292). Subjects were students at the California Institute of Technology who were recruited for the experiment and were told that they would be paid. The instructions were read to the subjects. Afterward, the markets were opened through a computerized market in the Caltech Laboratory for Experimental Economics and Political Science. All markets were organized as computerized multiple unit double auctions (MUDA), as described in Plott (1991). Subjects were trained to use the computer in electronic markets through the software tutorial programs contained in the general MUDA package. The incentive charts were organized ${ }^{3}$ such that it is reasonable to assume that the fact that the market demand function was stationary over all periods was public information. The incentive charts of suppliers were such that the supply curve shift could not have been detected by the demand side of the market until it was possibly revealed through the behavior of the market itself. ${ }^{4}$

Two of the experiments (022292) and (030292) were conducted exactly according to plan, but a mistake made by one of the suppliers in the third experiment (021592) prevents a direct comparison of small parts of the data with the other two experiments. The data from the third experiment are analyzed separately in the overall analysis because this experiment reveals an interesting phenomenon that is discussed independently. While the numbers of experiments may seem small, there are still a large number of observations because of the design. Each experiment involved parameter shifts, which can be viewed as additional experiments. The dynamic results are strong. The results closely conform to the results of Plott and George. Without a clear idea of what could be learned from additional experiments, the decision was made to stop with the three experiments.

\footnotetext{
${ }^{3}$ Physically, the charts were large and no new incentive charts were passed out.

${ }^{4}$ It was possible to shift the supply curve without new charts. The form of the charts was public information.
} 
All experiments were conducted under the same format of parameters and parameter changes. The first nine periods (periods 0 through 8 ) were conducted under supply conditions $S_{1} S_{1}$. A shift in supply to $S_{2} S_{2}$ occurred before the opening of period 9 (which was really the 10 th period) and remained in place until the end of the experiment. In summary, the experimental conditions were as follows.

Experiment 021592. Periods 0 through 8, supply $S_{1} S_{1}$ was operative, and periods 6 and 7 were skipped; Periods 9 through 19, supply $S_{2} S_{2}$ was operative.

Experiment 022292. Periods 0 through 8, supply $S_{1} S_{1}$ was operative; periods 9 through 19 , supply $S_{2} S_{2}$ was operative; a guarantee of the volume of others at 15 units was implemented at the start of period 15, thereby changing the demand curve to $D_{2} D_{2}$.

Experiment 030292. Periods 0 through 8, supply $S_{1} S_{1}$ was operative; periods 9 through 18 , supply $S_{2} S_{2}$ was operative.

The different period structure of experiment 021592 reflected the misunderstanding by one subject seller. This seller thought that selling all units listed on the incentive sheet was necessary. Theoretically, this would be interpreted as a substantial shift to the right of $S_{1} S_{1}$ that moves all interior equilibria to the right. Of course, during the first periods, the high volume (e.g., 40 units) was noticed by the experimenters. However, the possibility that a subject might be confused was not really considered by the experimenters at first. Instead, the experimenters thought that the market had found the stable equilibrium that exists at the point $(40,273)$. This particular equilibrium would have been very costly to the experimenters, and a decision was made to save money and eliminate periods 6 and 7. If the market was resting at that equilibrium, little was to be learned by letting it continue through the entire planned periods. The subjects were told that, due to a computer problem, periods 6 and 7 would be opened and then immediately closed without trade and that the subjects should simply mark out those periods on the incentive charts. They were told that the experiment would resume at period 8 . Period 8 was chosen because it is one period before the parameter shift to the $S_{2} S_{2}$ supply curve. While periods 6 and 7 were being opened and closed, a spot check of subject records revealed the confused subject. Thus, before the beginning of period 8 , the confusion was discovered and the subject was told that it was not necessary to sell everything. After this, the experiment proceeded as planned. Of course, all subjects had learned from the market in the first several periods that the market could sustain a high volume. In particular, the buyers, who did not know of the supply shift, were aware of the possibility.

\section{Results}

The time series from all three experiments are displayed in Figures 4-6. Shown on the horizontal axis is time in seconds. The vertical axis is price. The circles represent contracts. The vertical lines are the divisions between periods. The horizontal lines are the most important equilibria. The bottom of the figures contain average prices per period and volumes.

The central conclusion summarized by the two formal result statements is that Marshallian stability, as opposed to Walrasian, is the appropriate model for environments like the one under study. The results are supported by the visual representation of the data. The time series from the two central experiments (022292 and 030292) are contained in Figures 4 and 5. In both experiments under $S_{1} S_{1}$, the time series reveals the convergence to the nearest stable Marshallian equilibrium point at $(176,12)$. This equilibrium is Walrasian unstable, but it is Marshallian 


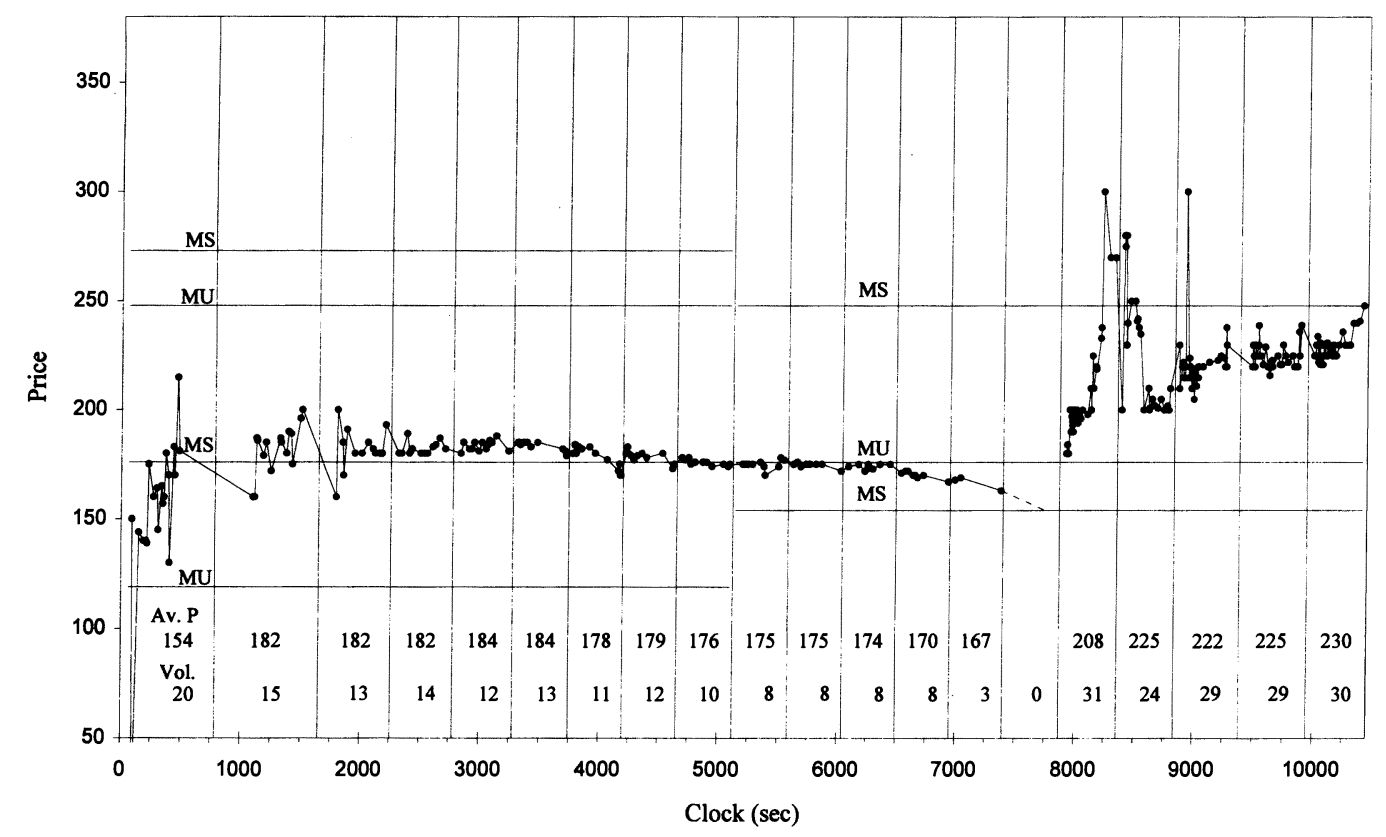

Figure 4. Contract Time Series Experiment 022292

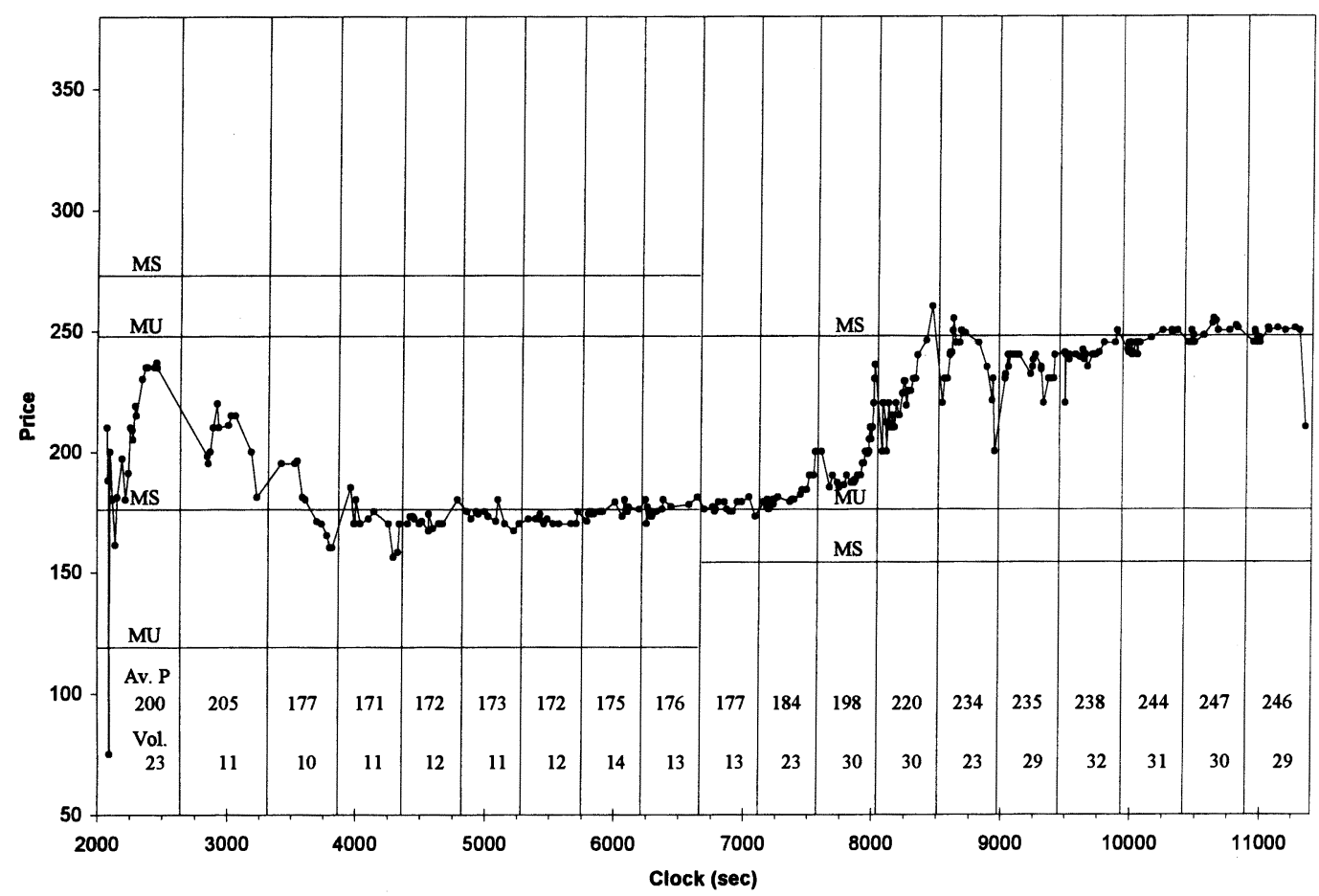

Figure 5. Contract Time Series Experiment 030292 


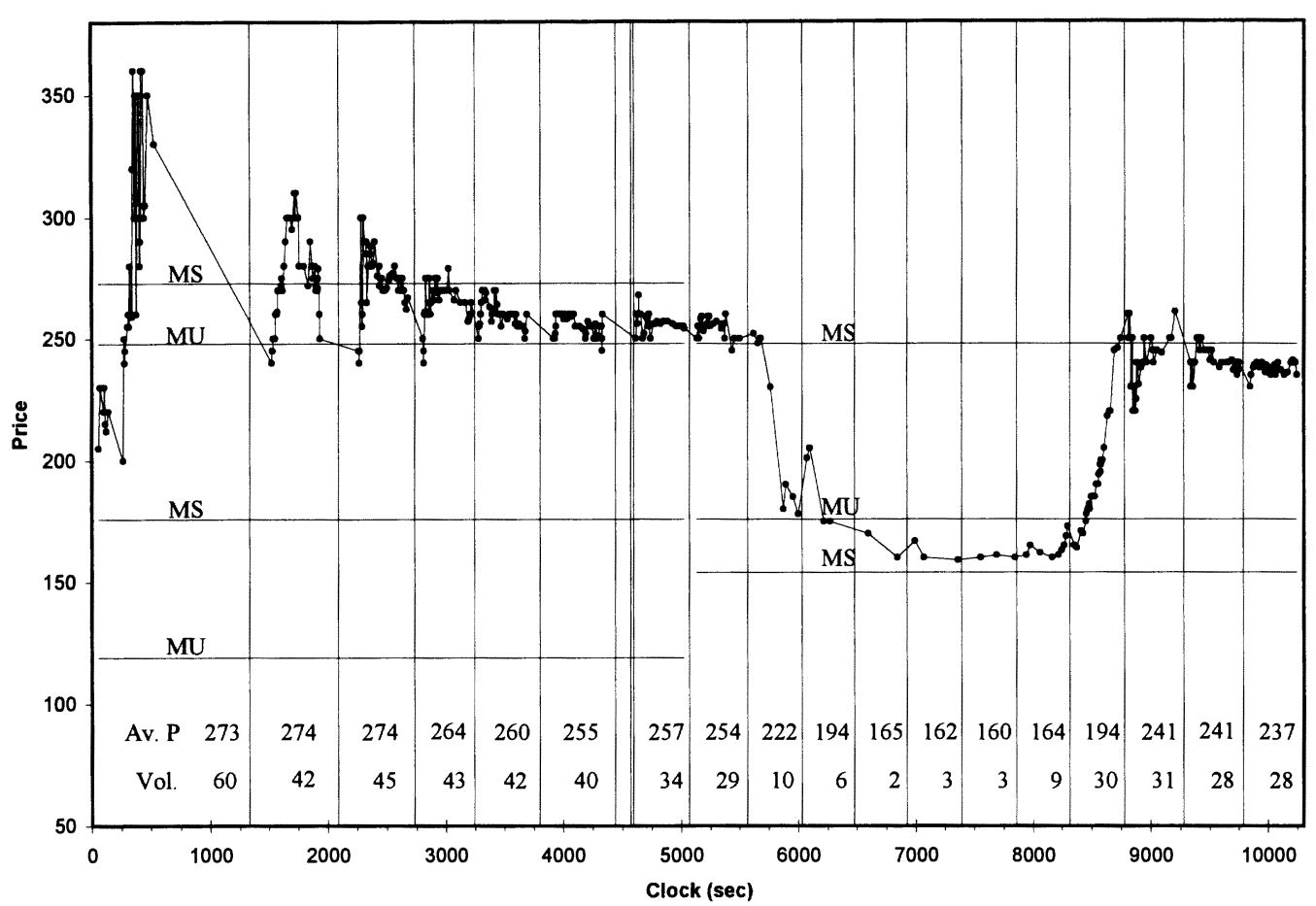

Figure 6. Contract Time Series Experiment 021592

stable. The supply shift $S_{2} S_{2}$ that occurs in period 9 of both experiments is accompanied by a movement away from the old equilibrium (which is now Walrasian stable) toward one of the two neighboring stable Marshallian (unstable Walrasian) equilibria. In experiment 022292, the convergence is downward toward point $a^{\prime}$ at $(154,0)$, and in 030292, the convergence is upward toward point $c$ at $(248,30)$. The data from experiment 021592 are in Figure 6 . When the model is adjusted for the mistake of the seller at the first part of this experiment, a Marshallian stable equilibrium appears near point $c$. As can be seen, the data are converging toward this area. After shifts, the data fall away from the uppermost stable Marshallian equilibrium, through the stable Walrasian equilibrium, to the lower stable Marshallian equilibrium. Then the data return to the upper stable Marshallian equilibrium.

RESUlt 1. The law of supply and demand accurately predicts points of equilibration.

SUPPORT. In both of the central experiments (022292) and (030292) under supply $S_{1} S_{1}$ before a parameter shift (periods 0 through 8 ), the time series reveals the convergence to the nearest stable Marshallian (and unstable Walrasian) equilibrium point $b$ at $(176,12)$. In experiment 02292 , the volume is within 2 units of the equilibrium volume of 12 units for the periods 2 through 8 and the average price is within 8 francs (less than 5\%) of the equilibrium price of 176 for periods 1 through 8 and within 3 francs (less than 2\%) for periods 6, 7, and 8. In experiment 030292 , the volume is within 2 units of the equilibrium volume of 12 units for periods 1 through 8 and the average price is within 5 francs (less than 3\%) of 176 for periods 2 through 8 and within 1 franc (less than $1 \%$ ) for periods 7 and 8 .

After the supply shift to $S_{2} S_{2}$, the data in all three experiments converge toward one of the neighboring stable Marshallian (unstable Walrasian) equilibria. In experiment 022292, by period 
Table 3. Estimated Coefficients ( $t$-Statistics)

\begin{tabular}{|c|c|c|c|c|c|c|c|c|c|c|}
\hline & \multicolumn{5}{|c|}{$\begin{array}{l}\quad \text { Marshallian Model } \\
Q_{t}-Q_{t-1}=a+b\left[P_{D}\left(Q_{t-1}\right)-P_{s}\left(Q_{t-1}\right)\right]\end{array}$} & \multicolumn{5}{|c|}{$\begin{array}{c}\text { Walrasian Model } \\
P_{t}-P_{t-1}=a+b\left[D\left(P_{t-1}\right)-S\left(P_{t-1}\right)\right]\end{array}$} \\
\hline & $a$ & $b$ & $R^{2}$ & $D_{w}$ & $N$ & $a$ & $b$ & $R^{2}$ & $d_{w}$ & $N$ \\
\hline 021592 & $\begin{array}{l}-1.04 \\
(-0.32)\end{array}$ & $\begin{array}{c}-0.28 \\
(-0.95)\end{array}$ & 0.10 & 1.36 & 10 & $\begin{array}{l}-1.02 \\
(-0.12)\end{array}$ & $\begin{array}{c}0.52 \\
(0.28)\end{array}$ & 0.01 & 0.92 & 10 \\
\hline 022292 & $\begin{array}{l}-1.28 * \\
(-2.29)\end{array}$ & $\begin{aligned} 0.17^{*} \\
(2.85)\end{aligned}$ & 0.35 & 2.34 & $17^{\mathrm{a}}$ & $\begin{array}{l}-1.74 \\
(-1.38)\end{array}$ & $\begin{array}{l}-1.39 * * \\
(-3.07)\end{array}$ & 0.40 & 1.64 & $16^{\mathrm{a}}$ \\
\hline 030292 & $\begin{array}{c}-0.93 \\
(-0.85)\end{array}$ & $\begin{array}{r}0.24^{*} \\
(2.65)\end{array}$ & 0.32 & 1.74 & 17 & $\begin{array}{l}-6.84^{*} \\
(-2.20)\end{array}$ & $\begin{array}{l}-3.44 * * \\
(-3.62)\end{array}$ & 0.47 & 1.39 & 17 \\
\hline
\end{tabular}

The coefficients reported here were computed by OLS. Using Table 1, the theoretical demands and supplies were calculated as follows: For the Marshallian model, the observed quantity for the period was used to find the period's theoretical market demand and supply. The Walrasian model was operationalized in a similar fashion, using the average transaction price of the period (rounded to the nearest integer). For both market demand and supply, the maximum quantity for which the induced market demand or supply did not exceed the observed market price was used for $D(P)$ and $S(P)$, respectively. For clarity, an example is the following: For period 3 in experiment 022292 , we have that the observed quantity is 14 and the rounded average price is 182 , and for period 4 in experiment 022293 we have that the observed quantity is 12 and the rounded average price is 184 . These data lead to the reexpressed data, which are used in the regressions reported above, of $Q_{4}-Q_{3}=-2, P_{4}-P_{3}=2, P_{D}\left(Q_{3}\right)=187, P_{S}\left(Q_{3}\right)=191, D\left(P_{3}\right)=12$, and $S\left(P_{3}\right)$ $=12$.

a The number of observations differs for the two regressions on 022292 due to the absence of any transactions in period

14. Thus, there is a total quantity but no average price.

* Statistically distinct from 0 at 0.05 level.

** Statistically distinct from 0 at 0.01 level.

13 , the average price and volume are $(167,3)$, and by period 14 , the volume is zero, which is near the equilibrium point $a^{\prime}$ at $(154,0)$. After the demand shifts to $D_{2} D_{2}$, the data converge toward the equilibrium $c$ at $(248,30)$. For the final three periods, the volume is within one unit and the average price is within $11 \%$. During the final three periods of experiment 030292 , the volume is within one unit and the average price is within $2 \%$ of the equilibrium point $c$.

In experiment 021592 , after the subject's misunderstanding was corrected, the volume is within two units for the final four periods, $16,17,18$, and 19. The average price is within $5 \%$ of the equilibrium point $c$ at $(248,30) . Q E D$.

The next conclusion is that the Marshallian model, and not the Walrasian model, captures the nature of the equilibration process; that is, the dynamics are Marshallian and not Walrasian since the convergence is toward the Marshallian stable equilibrium points.

Result 2. Price and quantity movements are in the direction predicted by the Marshallian model and not in the direction predicted by the Walrasian model.

SUPPORT. Table 3 contains the estimates of the two dynamic models for experiments 022292 and 030292. Estimates for experiments 022292 and 030292 are calculated separately for different sets of parameters. In Table 3, the estimate term for the Marshallian model $b_{\mathrm{M}}$ is always positive. It is significant (95\% confidence interval) for both 022292 and 030292 . Thus, the data support the Marshallian model. Contrary to prediction of the Walrasian dynamic model, the adjustment term $b_{\mathrm{w}}$ is negative for both 022292 and 030292 . It is significant for both data sets. Thus, the Walrasian model can be rejected in favor of the Marshallian model. Pooled data yield even stronger support for the result. $Q E D$.

The support for the Marshallian model is not all positive. The model predicts zero intercept 
$a_{\mathrm{M}}$. However, as can be seen from Table $3, a_{\mathrm{M}}$ is systematically negative and significant $(95 \%$ confidence interval for 022292). The next observations might help account for the inaccuracies.

OBSERVATION. The dynamics of price adjustment have a memory. Information in the adjustment process is not simply local information of the recent past.

SUPPORT. The support for this observation comes from experiment 021592 in which a subject was confused for the first few periods. Notice in Figure 6 that the data start with high prices and volume due to the implicit change in parameters of the one supplier. This change, in essence, creates a stable equilibrium until period 8 , when the confusion was removed. It is interesting to note that, during period 8 , the market is resting at an unstable Marshallian equilibrium. When the shift occurs at period 9, the equilibrium becomes Marshallian stable and, during period 9, the market stays near the equilibrium. However, in order to get to the highpriced equilibrium, the market must move away from the stable Marshallian equilibrium of zero volume that exists at point $a^{\prime}$ on the boundary. The high-priced stable equilibrium is not sustained. A few data points that are movements away from the stable Marshallian equilibrium take the systems into the unstable ranges. The fall in prices and volume that occurs in periods 10,11 , and 12 represents general movements toward the Marshallian stable boundary equilibrium. Of course, the fact that any volume exists at all during these periods is in defiance of the dynamic pressures of the Marshallian model. The small volumes that occurred in periods 13 and 14, when the market price falls to the lowest levels, are due to the buying behavior of a single agent. The action of one buyer constitutes $100 \%$ of the volume in periods 12,13 , and 14. It is natural to assume that this buyer is trying to signal other buyers to get the volume up so the market volume would be like the profitable experiences during the first periods of the experiment at a volume of 30 units. The hint is then picked up by other buyers in period 15 . The volume and price move through the stable Walrasian (Marshallian unstable) equilibrium at $(176,12)$ and continue to converge to the high level Marshallian stable equilibrium near $(248$, 30). $Q E D$.

This observation is particularly interesting for two reasons. First, it demonstrates that the dynamics of adjustment involve memories of a sort not captured by either the Marshallian or the Walrasian models of dynamics. Second, if game theory is to be successful, it must allow for the possibility that the selection of equilibrium can occur on either side of the market. The observation identifies a case in which the possibility of "leadership" instigated by a buyer resulted in equilibrium selection. By contrast, the literature (Becker 1991; Karni and Levin 1994) assumes that the selection in the case of fad-like preferences will come from sellers alone. It is rather interesting to note that even though these papers make solid contributions to the abstract understanding and anatomy of the economics of fad-like environments, their presumption about the market dynamics is wrong and their presumption about the application of game theory is wrong as well. Clearly, results such as those reported here are of interest to theory.

\section{Closing Remarks}

Markets with externalities and fad-like incentives exhibit many of the qualities predicted by the competitive law of supply and demand. Equilibria of the competitive model do a good job of capturing the points of price convergence. The power of the equilibrium model is rather 
surprising since the demand curve construction requires very strong assumptions along the lines of rational expectations. Nevertheless, equilibration is observed.

Markets with upward-sloping demands can contain both stable and unstable equilibria. If the upward slope is due to an externality like a Marshallian fad, then the conditions under which instability will be observed and the associated dynamics are best captured by the Marshallian concept of instability, as opposed to the Walrasian concept. The importance of the Marshallian concept seems to have been lost to the theoretical literature, which has focused on the Walrasian concept and on game theoretic selection models. These data suggest a need for theorists to revisit the classical Marshallian theory.

The theoretical symmetry that exists between the upward-sloping demand and the downward-sloping supply exists in behavior. The results reported here replicate the discovery of Plott and George (1992) and extend the result to the upward-sloping demand. The properties of equilibration known to exist in the downward-sloping supply case of a Marshallian external economy exist with equal strength in the upward-sloping demand case of fad-like incentives. Thus, in these environments, the competitive market law of supply and demand appears to work with the generality for which it was developed. The conditions under which instability is observed are predicted by the Marshallian model of market adjustment and not the Walrasian model. A major outstanding issue is whether or not the Marshallian theory of stability holds in the backward-bending case. At this point, there appears to be no detailed theory of the dynamics. Indeed, one might note that the Walrasian model (with the wrong sign) yields higher $R^{2}$ than the Marshallian model. Thus, the door is wide open for theoretical improvements.

An error by a subject provided a glimpse at what could be one of the most important aspects of the study. The nature of market equilibrium selection is not determined by local information and dynamics alone. Collective experience, signaling through market actions, and coordinated efforts to overcome a "local" prisoner's dilemma may all play a part in the complex dynamics of equilibration.

\section{Appendix}

\section{Instructional Material and Parameters}

Sellers were given standard instructions such as those found in Plott (1991). The only differences are the numbers used in the examples. Buyer instructions are special because of the nature of the externality. These are reproduced in this appendix. A quiz and a period zero were both administered to check subjects' understanding of the accounting system. The Redemption Sheets contain the parameters of buyers. These are important because slight adjustments from the continuous model were made in order to obtain the quantified incentives used in the experiment. In addition to a sheet with marginal redemption value information, buyers were given sheets with the total of redemption values.

Specific Instructions to the Buyers

During each market period, you are free to purchase as many units as you might want. The profit from each purchase (which is yours to keep) is computed by taking the difference between the redemption value and purchase price of the unit bought. Note that you may buy a unit for a price that exceeds the redemption value. Therefore,

$$
\text { [your profit }=(\text { redemption value })-(\text { purchase price })] \text {. }
$$

Your redemption value depends on your volume and the volume of others. This means that, when you buy units, you will not know your redemption values with certainty. Your redemption values will be known only at the end of a period when the total volume of purchases is known. Examine your Redemption Sheet. If the volume of others is zero, that is, you were the only one who bought units, then the redemption value of each of your units is found in the column labeled 0 . If the volume of others is 23 , then the redemption value of each of your units is found in the column labeled 23 . 
Suppose, for example, that you bought 2 units in a market in which a total of 10 units were bought. Find the appropriate column in your Example Redemption Sheet (as illustrated on the chalkboard). Since the volume of others is eight units, the redemption value for you of the first unit is 6000 and the redemption value of the second unit is 4500 . If you bought each unit for 3500 , your profit is

$$
\begin{aligned}
\text { profit from first unit } & =6000-3500=2500 \\
\text { profit from second unit } & =4500-3500=1000 \\
\text { total profit } & =2500+1000=3500 .
\end{aligned}
$$

The blanks on the Record of Purchases and Earnings will help you record your profit. The purchase price of the first unit you buy during the first period should be recorded in row 2. Do the same (in the appropriate rows) for any additional units bought in this period. At the end of the period, enter the market volume of the period in row A, enter your volume in row B, and subtract row B from row A to determine the resulting volume of others to enter in row C. Then look on your Redemption Sheet to find your unit redemption values. On the record of Purchases and Earning Sheets, enter the redemption value of the first unit in row 1. You should then record the profit on this sale as directed in row 3. After computing the profit for each unit bought, record the total profit for that period in the last row on the page, row 31. Subsequent periods should be recorded similarly in the appropriate column (period 1 in column 1, period 2 in column 2, etc.).

\section{Quiz Sellers}

1. If in period 1 , you sold two units for 1800 each, what would be your profit

for the period ?

Complete the form.

2. If in period 2, you sold one unit for 1000 what would be your profit

for the period ?

\section{Quiz Buyers}

1) If you bought one unit in a market in which six (6) units are purchased in total (your unit plus units purchased by others)

a) What is the volume of others $?$

b) What is the redemption value of your second unit ?

2) If you bought two units in a market in which no other units are purchased

a) What is the volume of others $?$

b) What is the redemption value of your next unit ? 


\section{Redemption Sheet $\quad$ Buyer \# 0 and 2}

\begin{tabular}{|l|r|r|r|r|r|r|r|r|r|}
\hline & \multicolumn{8}{|c|}{ Volume of Others } \\
\cline { 2 - 10 } & 0 & 1 & 2 & 3 & 4 & 5 & 6 & $\ldots$ & 32 \\
\hline 1st & 124 & 140 & 146 & 152 & 158 & 164 & 180 & $\ldots$ & 386 \\
\hline 2nd & 108 & 124 & 130 & 136 & 142 & 148 & 164 & $\ldots$ & 370 \\
\hline 3rd & 92 & 108 & 114 & 120 & 126 & 132 & 148 & $\ldots$ & 354 \\
\hline 4th & 76 & 92 & 98 & 104 & 110 & 116 & 132 & $\ldots$ & 338 \\
\hline 5th & 60 & 76 & 82 & 88 & 94 & 100 & 116 & $\ldots$ & 322 \\
\hline 6th & 44 & 60 & 66 & 72 & 78 & 84 & 100 & $\ldots$ & 306 \\
\hline 7th & 28 & 44 & 50 & 56 & 62 & 68 & 84 & $\ldots$ & 290 \\
\hline 8th & 12 & 28 & 34 & 40 & 46 & 52 & 68 & $\ldots$ & 274 \\
\hline
\end{tabular}

\section{Redemption Sheet Buyer \# 1 and 4}

\begin{tabular}{|l|r|r|r|r|r|r|r|r|r|}
\hline & \multicolumn{8}{|c|}{ Volume of Others } \\
\cline { 2 - 10 } & 0 & 1 & 2 & 3 & 4 & 5 & 6 & $\ldots$ & 32 \\
\hline 1st & 116 & 122 & 128 & 134 & 140 & 156 & 162 & $\ldots$ & 368 \\
\hline 2nd & 100 & 106 & 112 & 118 & 124 & 140 & 146 & $\ldots$ & 352 \\
\hline 3rd & 84 & 90 & 96 & 102 & 108 & 124 & 130 & $\ldots$ & 336 \\
\hline 4th & 68 & 74 & 80 & 86 & 92 & 108 & 114 & $\ldots$ & 320 \\
\hline 5th & 52 & 58 & 64 & 70 & 76 & 92 & 98 & $\ldots$ & 304 \\
\hline 6th & 36 & 42 & 48 & 54 & 60 & 76 & 82 & $\ldots$ & 288 \\
\hline 7th & 20 & 26 & 32 & 38 & 44 & 60 & 66 & $\ldots$ & 272 \\
\hline 8th & 4 & 10 & 16 & 22 & 28 & 44 & 50 & $\ldots$ & 256 \\
\hline
\end{tabular}

\section{Redemption Sheet $\quad$ Buyer \# 3 and 5}

\begin{tabular}{|l|r|r|r|r|r|r|r|r|r|}
\hline & \multicolumn{10}{|c|}{ Volume of Others } \\
\cline { 2 - 10 } & 0 & 1 & 2 & 3 & 4 & 5 & 6 & $\ldots$ & 32 \\
\hline 1st & 120 & 126 & 132 & 148 & 154 & 160 & 166 & $\ldots$ & 372 \\
\hline 2nd & 104 & 110 & 116 & 132 & 138 & 144 & 150 & $\ldots$ & 356 \\
\hline 3rd & 88 & 94 & 100 & 116 & 122 & 128 & 134 & $\ldots$ & 340 \\
\hline 4th & 72 & 78 & 84 & 100 & 106 & 112 & 118 & $\ldots$ & 324 \\
\hline 5th & 56 & 62 & 68 & 84 & 90 & 96 & 102 & $\ldots$ & 308 \\
\hline 6th & 40 & 46 & 52 & 68 & 74 & 80 & 86 & $\ldots$ & 292 \\
\hline 7th & 24 & 30 & 36 & 52 & 58 & 64 & 70 & $\ldots$ & 276 \\
\hline 8th & 8 & 14 & 20 & 36 & 42 & 48 & 54 & $\ldots$ & 260 \\
\hline
\end{tabular}

Note: as volume of others increases, redemption value increases by 6 per unit. The exceptions are every fifth unit starting at 1 , at which point the increment is 16 as opposed to 6 .

Note: as volume of others increases, redemption value increases by 6 per unit. The exceptions are every fifth unit starting at 5 , at which point the increment is 16 as opposed to 6 .

Note: as volume of others increases, redemption value increases by 6 per unit. The exceptions are every fifth unit starting at 3 , at which point the increment is 16 as opposed to 6 . 
Seller unit cost in period $0-8$

\begin{tabular}{|c|r|r|r|r|r|r|}
\hline & \multicolumn{6}{|c|}{ Seller Number } \\
\cline { 2 - 7 } & 6 & 7 & 8 & 9 & 10 & 11 \\
\hline 1st & 128 & 132 & 136 & 116 & 120 & 124 \\
\hline 2nd & 140 & 144 & 148 & 156 & 164 & 172 \\
\hline 3rd & 196 & 188 & 180 & 220 & 212 & 204 \\
\hline 4th & 236 & 234 & 232 & 230 & 228 & 226 \\
\hline 5th & 244 & 246 & 248 & 238 & 240 & 242 \\
\hline 6th & 250 & 252 & 254 & 256 & 258 & 260 \\
\hline 7th & 266 & 264 & 262 & 272 & 270 & 268 \\
\hline 8th & 284 & 282 & 280 & 278 & 276 & 274 \\
\hline 9th & 292 & 294 & 296 & 286 & 288 & 290 \\
\hline 10th & 298 & 300 & 302 & 304 & 306 & 308 \\
\hline
\end{tabular}

Seller unit cost in period 9-20

\begin{tabular}{|c|r|r|r|r|r|r|}
\hline & \multicolumn{6}{|c|}{ Seller Number } \\
\cline { 2 - 7 } & 6 & 7 & 8 & 9 & 10 & 11 \\
\hline 1st & 160 & 162 & 164 & 154 & 156 & 158 \\
\hline 2nd & 166 & 168 & 170 & 172 & 174 & 176 \\
\hline 3rd & 181 & 180 & 178 & 184 & 183 & 182 \\
\hline 4th & 200 & 195 & 191 & 188 & 186 & 185 \\
\hline 5th & 228 & 236 & 244 & 206 & 212 & 218 \\
\hline 6th & 252 & 260 & 268 & 276 & 284 & 292 \\
\hline 7th & 316 & 308 & 300 & 340 & 332 & 324 \\
\hline 8th & 388 & 380 & 372 & 364 & 356 & 348 \\
\hline 9th & 420 & 420 & 436 & 396 & 404 & 412 \\
\hline 10th & 444 & 452 & 460 & 468 & 476 & 484 \\
\hline
\end{tabular}

Record of Sales and Profits, Seller No. 6

\begin{tabular}{|c|c|c|c|c|c|c|c|c|c|c|c|c|c|}
\hline $\begin{array}{l}\text { Unit } \\
\text { Sold }\end{array}$ & & $\begin{array}{l}\text { Trading Period } \\
\text { Number }\end{array}$ & & & 2 & & 4 & & & 7 & 8 & 9 & \\
\hline \multirow{3}{*}{1} & 1 & Selling Price & & & & & & & & & & & \\
\hline & 2 & Cost of 1st unit & 128 & 128 & 128 & 128 & 128 & 128 & 128 & 128 & 128 & 160 & 160 \\
\hline & 3 & $\begin{array}{l}\text { Profit } \\
\text { (row 1 - row 2) }\end{array}$ & & & & & & & & & & & \\
\hline \multirow{3}{*}{2} & 4 & Selling Price & & & & & & & & & & & \\
\hline & 5 & Cost of 2 nd unit & 140 & 140 & 140 & 140 & 140 & 140 & 140 & 140 & 140 & 166 & 166 \\
\hline & 6 & $\begin{array}{l}\text { Profit } \\
\text { (row } 4 \text { - row 5) }\end{array}$ & & & & & & & & & & & \\
\hline \multicolumn{14}{|l|}{ : } \\
\hline \multirow{3}{*}{10} & 28 & Selling Price & & & & & & & & & & & \\
\hline & 29 & Cost of 10th unit & 298 & 298 & 298 & 298 & 298 & 298 & 298 & 298 & 298 & 444 & 444 \\
\hline & 30 & $\begin{array}{l}\text { Profit } \\
\text { (row } 28 \text { - row 29) }\end{array}$ & & & & & & & & & & & \\
\hline & 31 & Total per period & & & & & & & & & & & \\
\hline \multicolumn{6}{|l|}{ Name } & \multicolumn{5}{|c|}{ Soc. Sec. No. } & \multicolumn{3}{|c|}{ Total Payment } \\
\hline
\end{tabular}

\section{References}

$\rightarrow$ Becker, Gary S. 1991. A note on restaurant pricing and other examples of social influence on price. Journal of Political Economy 99:1109-16.

Harrison, Glen W., Elizabeth Hoffman, E. E. Rutstrom, and Matthew L. Spitzer. 1987. Coasian solutions to the externality problem in experimental markets. Economic Journal 97:388-402.

Henderson, James M., and Richard E. Quandt. 1980. Micro-economic theory: A mathematical approach. Third edition. New York: McGraw-Hill. 
$\rightarrow$ Karni, Edi, and Dan Levin. 1994. Social attributes and strategic equilibrium: A restaurant pricing game. Journal of Political Economy 102:822-40.

$\rightarrow$ Plott, Charles R. 1983. Externalities and corrective taxes. The Economic Journal 93:106-27.

Plott, Charles R. 1991. A computerized laboratory market system and research support systems for the Multiple Unit Double Auction. Caltech Social Science Working Paper No. 783.

Plott, Charles R., and Glen George. 1992. Marshallian vs. Walrasian stability in an experimental market. Economic Journal 102:437-60.

Takayama, Akira. 1974. Mathematical economics. Hinsdale, IL: Dryden Press. 